\title{
Adipose tissue mass and location affect circulating adiponectin levels
}

\author{
A. T. Turer - A. Khera - C. R. Ayers - C. B. Turer - \\ S. M. Grundy • G. L. Vega • P. E. Scherer
}

Received: 19 May 2011 / Accepted: 14 June 2011 / Published online: 22 July 2011

(C) Springer-Verlag 2011

\begin{abstract}
Aims/hypothesis Plasma levels of adiponectin are inversely associated with body mass. We hypothesised that adipose tissue distribution and body composition influences adiponectin levels.

Methods We assessed plasma adiponectin concentrations and dual-energy X-ray absorptiometry (DEXA) measurements of body composition among 2,820 participants from the Dallas Heart Study.

Results Among both women and men, adiponectin levels were higher in whites than in either Hispanics or AfricanAmericans (for women: median $9.99 \mu \mathrm{g} / \mathrm{ml}$ [25th,75th percentile $7.11,13.77]$ vs $7.56 \mu \mathrm{g} / \mathrm{ml}[5.05,9.98]$ vs $6.39 \mu \mathrm{g} / \mathrm{ml}[4.37,9.41]$, respectively, $p<0.0001$; for men: $6.43 \mu \mathrm{g} / \mathrm{ml}[4.66,9.19]$ vs $5.55 \mu \mathrm{g} / \mathrm{ml}[3.64,7.50]$ vs $5.03 \mu \mathrm{g} / \mathrm{ml}[3.39,7.28], p<0.0001)$. In univariate analysis, each individual component of body mass was inversely
\end{abstract}

\section{A. T. Turer $(\bowtie) \cdot$ A. Khera}

Department of Medicine, Division of Cardiology,

University of Texas Southwestern Medical Center,

5323 Harry Hines Blvd,

Dallas, TX 75390-8521, USA

e-mail: Aslan.Turer@UTSouthwestern.edu

\section{A. Khera $\cdot$ C. R. Ayers}

Donald W. Reynolds Cardiovascular Clinical Research Center,

University of Texas Southwestern Medical Center,

Dallas, TX, USA

\section{B. Turer}

Department of Pediatrics, Division of General Pediatrics, University of Texas Southwestern Medical Center,

Dallas, TX, USA

\section{B. Turer}

Department of Medicine, Division of General Internal Medicine, University of Texas Southwestern Medical Center,

Dallas, TX, USA associated with adiponectin. After multivariate analysis, adiponectin levels were found to be positively associated with lower extremity fat, whether expressed in absolute mass (for women: $\beta=0.055, p<0.0001$; for men: $\beta=0.061$, $p<0.0001$ ), or as a relative proportion (for women: $\beta=0.035, p<0.0001$; for men: $\beta=0.034, p<0.0001)$. This association was consistent across ethnicities. Conversely, adiponectin was negatively correlated with truncal fat, both in absolute (for women: $\beta=-0.039, p<0.0001$; for men: $\beta=-0.044, p<0.0001$ ) and relative terms (for women: $\beta=-0.027, p<0.0001$; for men $\beta=-0.033, p<0.0001$ ). At the extreme of body mass, higher degrees of lower extremity and truncal adiposity were associated with higher levels of adiponectin.

Conclusions/interpretation These data suggest that the location of adipose depots differentially influences circulating adiponectin concentrations - $\mathrm{a}$ finding observed

\section{S. M. Grundy · G. L. Vega}

Center for Human Nutrition,

University of Texas Southwestern Medical Center,

Dallas, TX, USA

\section{P. E. Scherer}

Department of Medicine, Touchstone Diabetes Center, University of Texas Southwestern Medical Center, Dallas, TX, USA

P. E. Scherer

Department of Cell Biology,

University of Texas Southwestern Medical Center,

Dallas, TX, USA 
across ethnicity and sex. Gross measures of body mass alone do not adequately account for adiponectin levels. This supports a role of adiponectin as a mediator of the positive effects of lower extremity adiposity on improvements in insulin sensitivity.

Keywords Adipokines - Adiponectin - Body composition . DEXA $\cdot$ Fat depots $\cdot$ Obesity

\section{Introduction}

Adiponectin is an adipokine constitutively produced at high levels by fat tissue. In animals, adiponectin has been shown to be anti-inflammatory, anti-apoptotic $[1,2]$ and to be an insulin-sensitiser [3-5]. These actions may be the result of a ceramide-lowering effect of adiponectin and its receptors ADIPOR1 and ADIPOR2 [6]. Cross-sectional studies in humans have consistently shown a relationship between higher adiponectin levels and lower risk for the development of type 2 diabetes [7] and its associated comorbidities, such as atherosclerosis [8-10] and hepatic steatosis [11, 12].

Although adiponectin is secreted by adipocytes, circulating levels are, paradoxically, inversely related to BMI [13]. However, BMI is a gross composite measure of adipose tissue, and there is ample evidence that the location of any given fat depot influences its effect on whole-body energy homeostasis [14-18]. As adiponectin levels associate with measures of insulin sensitivity, it is conceivable that different components of body composition are important determinants of adiponectin levels. Indeed, gross measures of adiposity alone may not completely account for variations of adiponectin concentrations. Here, we report on the association between adiponectin levels in circulation and individual measures of body composition in a large multi-ethnic population-based cohort study.

\section{Methods}

Study population The details of recruitment and design of the Dallas Heart Study have been described previously by Victor et al. [19]. Briefly, this cohort is a multi-ethnic population-based sample of residents of Dallas County aged 18-65 years old, with a deliberate over-representation of African-Americans. An initial cohort of 6,101 individuals participated in an in-home survey. Of these, 3,398 participants of ages 30-65 years returned for a second visit to provide blood samples, and 2,971 individuals returned for a third visit where multimodality imaging, including body composition, was performed. Among the participants under investigation, the median time between the first and second visits was $17(10,57)$ days and $28(9,60)$ days between the second and third visits. There were no major differences in participant characteristics between those presenting at visits 2 and 3 [19]. Race/ethnicity was self-reported. Definitions of other major variables have been described previously [19]. Only African-American, Hispanic and white participants were included in this analysis because of the small number of other ethnicities. The present study population includes the 2,820 participants for whom we have measured total plasma adiponectin levels and for which body composition analysis by dual-energy X-ray absorptiometry (DEXA) was available. All participants provided written informed consent to participate in the study and the protocol was approved by the Institutional Review Board of the University of Texas Southwestern Medical Center at Dallas.
Table 1 Baseline characteristics of the Dallas Heart Study Cohort

Date are percentages or median (25th, 75th quartiles) values

\begin{tabular}{llll}
\hline Clinical variable & Entire cohort $(n=2,820)$ & Women $(n=1,568)$ & Men $(n=1,252)$ \\
\hline Age (years) & $45(38,52)$ & $45(37,53)$ & $44(38,52)$ \\
African-American (\%) & 49.2 & 52.6 & 48.5 \\
Hispanic (\%) & 17.2 & 17.8 & 16.5 \\
Hypertension (\%) & 35.2 & 36.5 & 33.4 \\
Hyperlipidaemia (\%) & 13.6 & 12.7 & 14.8 \\
Diabetes mellitus $(\%)$ & 11.5 & 11.7 & 11.4 \\
Current smoking $(\%)$ & 28.8 & 24.9 & 33.7 \\
BMI $\left(\mathrm{kg} / \mathrm{m}^{2}\right)$ & $29.3(25.5,34.1)$ & $30.4(25.8,36.2)$ & $28.4(25.1,31.9)$ \\
LDL-cholesterol $(\mathrm{mmol} / \mathrm{l})$ & $2.72(2.12,3.32)$ & $2.67(2.12,3.24)$ & $2.77(2.15,3.39)$ \\
HDL-cholesterol $(\mathrm{mmol} / \mathrm{l})$ & $1.24(1.04,1.50)$ & $1.32(1.11,1.58)$ & $1.14(0.96,1.35)$ \\
Triacylglycerol $(\mathrm{mmol} / \mathrm{l})$ & $1.10(0.77,1.65)$ & $1.04(0.75,1.49)$ & $1.18(0.80,1.89)$ \\
HOMA-IR & $2.95(1.62,4.99)$ & $3.12(1.71,5.20)$ & $2.72(1.52,4.74)$ \\
Adiponectin $(\mu \mathrm{g} / \mathrm{ml})$ & $6.59(4.43,9.68)$ & $7.75(5.02,10.92)$ & $5.56(3.81,8.10)$ \\
\hline
\end{tabular}


Body composition measurement DEXA scanning was performed with a Delphi W scanner (Hologic, Bedford, MA, USA) with a fan beam [14]. Images were analysed using Hologic Discovery software version 12.2 to determine fat and lean mass (which includes bone mineral content). Body regions were defined using standard anatomical partitions. The trunk was defined superiorly from below the chin, laterally by vertical lines through the glenoid fossa and lateral to the ribs, and inferiorly by oblique lines passing through the femoral necks and converging below the pubic symphysis. The lower extremities were defined as the region below these oblique lines comprising the legs and feet. Measures from the upper extremities and head were not used in this analysis, given their overall small contribution to total body mass.

Regional fat and lean mass is reported in $\mathrm{kg}$. The proportion of fat at each body region was calculated as fat mass/(fat+lean mass) for that particular area and expressed as a percentage.

Adiponectin measurements Blood samples were obtained from participants following an overnight fast and collected in EDTA-containing tubes. Plasma aliquots were stored at $-80^{\circ} \mathrm{C}$ until assays were performed. Total adiponectin levels were quantified using a commercially available sandwich enzymelinked immunosorbent assay (Millipore, Billerica, MA, USA) according to the manufacturer's specifications. The measured intra-assay CVs were between $1.0 \%$ and $7.4 \%$ and the interassay $\mathrm{CVs}$ between $2.4 \%$ and $8.4 \%$.

Statistical analysis The clinical, anthropomorphic and biochemical data of the study population are reported as either proportions or median values with 25 th and 75 th percentiles. Adiponectin levels were modelled following a natural logarithm transformation (log adiponectin) because of the non-parametric distribution of the data. Univariate correlations were expressed as Pearson correlation coefficients $(r)$. Multivariable linear regression models were generated using log adiponectin as a continuous dependent outcome variable. In the first set of models, adjustments were made for age, ethnicity, height and absolute fat and lean mass (in $\mathrm{kg}$ ) of the lower extremities and trunk. In the second set of models, adjustments were made for the relative proportion of truncal and lower extremity mass composed of fat (rather than absolute masses), in addition to age, ethnicity, height and total body mass. Given the significant difference in anthropometric features and adiponectin levels between sexes, separate models were created for men and woman. Additionally, as a sensitivity analysis, individual sex and ethnicity-specific models were tested. $p$ values $<0.05$ were considered statistically significant. All analyses were performed using SAS 9.2 (SAS Corporation, Cary, NC, USA).

\section{Results}

Clinical and body composition features of the study population Baseline characteristics of the study population, stratified by sex, are shown in Table 1 . There was a high prevalence of most traditional cardiovascular risk factors, including hypertension and diabetes, consistent with a multi-ethnic urban cohort. Levels of adiponectin (median [25th, 75th quartiles]) were significantly different between ethnicities, being higher in white than in either Hispanic or African-American women $(9.99 \mu \mathrm{g} / \mathrm{ml}$ [7.11, 13.77] vs $7.5 \mu \mathrm{g} / \mathrm{ml}[5.05,9.98]$ vs $6.39 \mu \mathrm{g} / \mathrm{ml}[4.37,9.41], p<$ $0.0001)$. Similar trends were seen in men $(6.43 \mu \mathrm{g} / \mathrm{ml}$ [4.66, 9.19] vs $5.55 \mu \mathrm{g} / \mathrm{ml}[3.64,7.50]$ vs $5.03 \mu \mathrm{g} / \mathrm{ml}[3.39$, 7.28], $p<0.0001$, for white, Hispanic and AfricanAmerican, respectively) (Fig. 1). The body composition measurements stratified by sex and ethnicity are shown in Table 2. Women had higher total fat mass and regional fat mass than men in each racial group.

Correlations between body composition and adiponectin levels For both men and women, adiponectin levels were negatively correlated with each measure of body composition in univariate analysis (Table 3). An inverse relationship with adiponectin existed for both lean and fat mass at each site, likely reflecting co-linearity of these measures.

Adjustment for coincidental fat and lean mass in multivariate analysis demonstrated significant independent associations of different body composition variables with adiponectin. As shown in Table 4, among women, adiponectin levels were
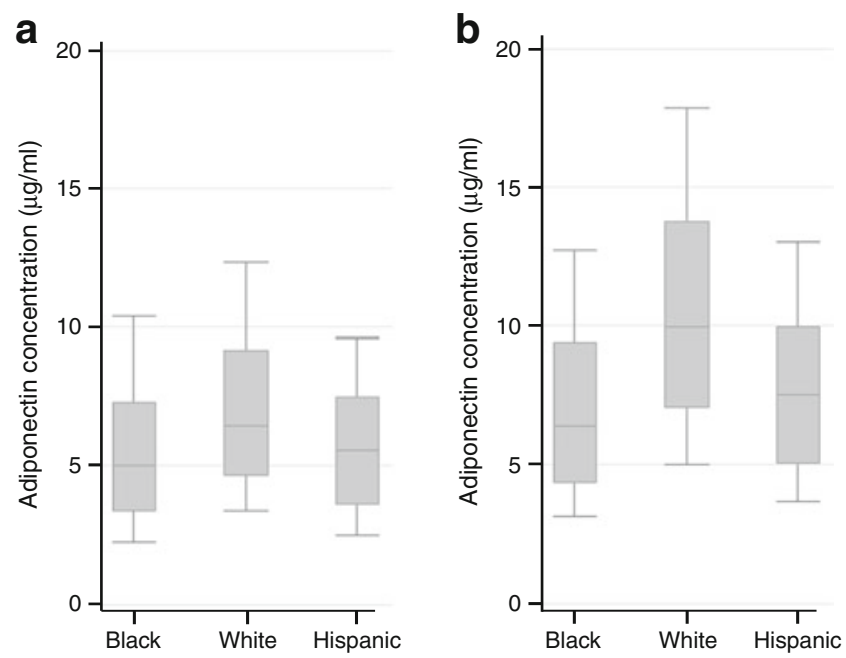

Fig. 1 Adiponectin levels for (a) men and (b) women in the Dallas Heart Study, stratified by ethnicity. Median (25th,75th percentile) values $(\mu \mathrm{g} / \mathrm{ml})$ are: women, black $6.39(4.37,9.41)$, white $9.99(7.11$, 13.77), Hispanic $7.56(5.05,9.98)$; men, black $5.03(3.39,7.28)$, white 6.43 (4.66, 9.19), Hispanic $5.55(3.64,7.50)$. The tenth and 90th percentiles are displayed as whiskers 


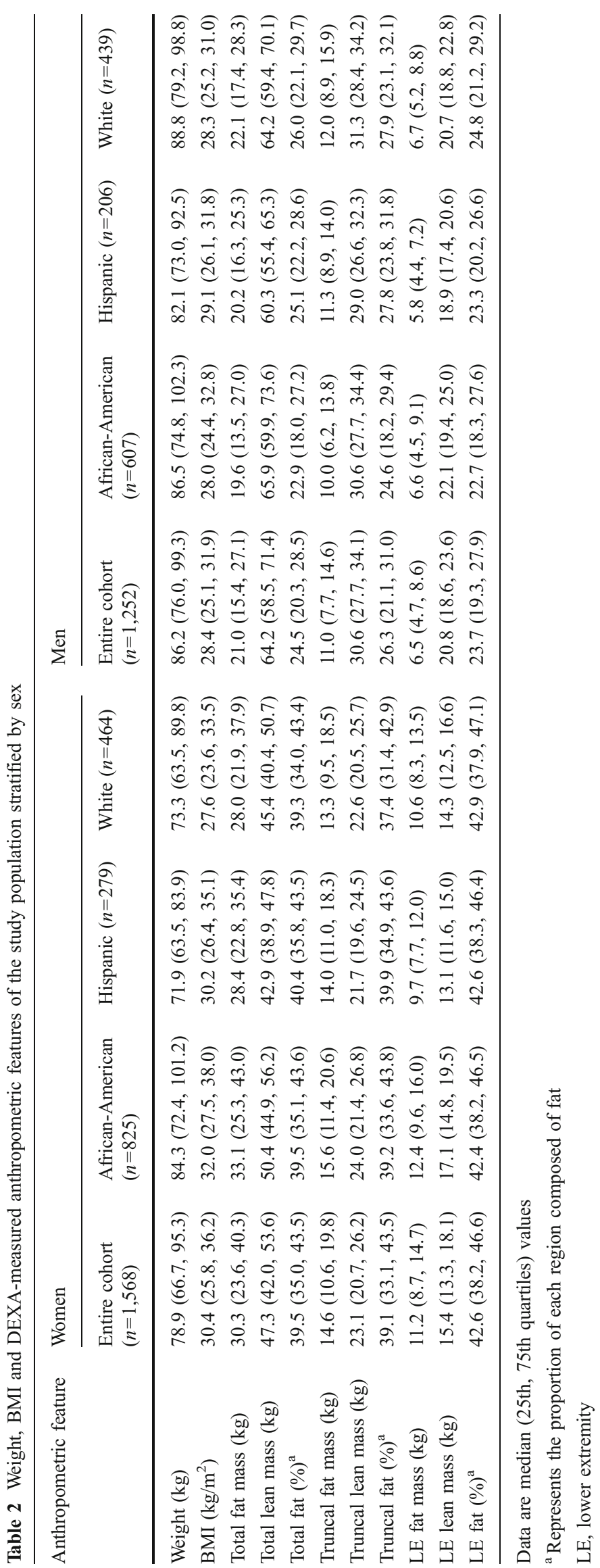


Table 3 Univariate correlations between aspects of body composition and $(\log )$ adiponectin concentrations stratified by sex

LE, lower extremity

positively associated with lower extremity fat mass $(\beta=0.055$, $p<0.0001)$, while they were negatively correlated with truncal fat $(\beta=-0.039, p<0.0001)$ and lower extremity lean mass $(\beta=-0.042, p<0.0001)$. Similarly in men, adiponectin levels were directly associated with lower extremity fat mass $(\beta=0.061, p<0.0001)$ and inversely associated with truncal fat $(\beta=-0.044, p<0.0001)$ and lower extremity lean mass $(\beta=-0.036, p<0.0001)$.

Table 5 shows the associations between adiponectin and adiposity expressed as the percentage of fat for each body region. Significant positive associations were noted between adiponectin and the relative adiposity present in the lower extremities for both men $(\beta=0.034, p<0.0001)$ and women $(\beta=0.035, p<0.0001)$. Conversely, the percentage of truncal fat was inversely related to adiponectin levels in men $(\beta=-0.033, p<0.0001)$ and women $(\beta=-0.027$, $p<0.0001)$. Adiponectin concentrations by sex- and ethnicity-stratified quartiles of percentage lower extremity and truncal fat across quartiles of body fat is shown in Fig. 2.

As Hispanic and black ethnicities were both associated with lower adiponectin levels, we constructed additional ethnicity- and sex-specific models for absolute (Table 6) and proportional (Table 7) fat measures. The magnitude of the association between lower extremity adiposity and adiponectin levels was remarkably similar across all subgroups while the inverse association between adiponectin and truncal fat was blunted among Hispanics (particularly Hispanic men).

Association between adiposity and adiponectin levels at the extreme of BMI To test the relationship between adiposity and adiponectin at the extreme of weight, we examined these measures in upper BMI extreme of cohort, defined as the upper tenth percentile by ethnicity and sex (median BMI $45.4 \mathrm{~kg} / \mathrm{m}^{2}$ for women and $37.2 \mathrm{~kg} / \mathrm{m}^{2}$ for men).

Table 4 Adjusted associations between body composition variables and (log) adiponectin concentrations in multivariable linear regression models stratified by sex

\begin{tabular}{lllll}
\hline Anthropomorphic feature $^{\mathrm{a}}$ & Women & & Men \\
\cline { 2 - 3 } & $\beta$ coefficient & $p$ value & & $\beta$ coefficient \\
\hline Truncal fat mass & -0.039 & $<0.0001$ & -0.044 & $<$ value \\
Truncal lean mass & -0.003 & 0.638 & 0.003 & 0.0001 \\
LE fat mass & 0.055 & $<0.0001$ & 0.061 & $<0.0001$ \\
LE lean mass & -0.042 & $<0.0001$ & -0.036 & $<0.0001$ \\
\hline
\end{tabular}

Models included anthropometric measures expressed as absolute masses

$\beta$ coefficients refer to the estimated change in $(\log )$ adiponectin $(\mu \mathrm{g} / \mathrm{ml})$ for each $\mathrm{kg}$ change in mass

${ }^{a}$ Model adjusted for age, ethnic background, height and all listed body composition variables simultaneously

LE, lower extremity 
Table 5 Adjusted associations between body composition variables and (log) adiponectin concentrations in multivariable linear regression models stratified by sex

\begin{tabular}{|c|c|c|c|c|}
\hline \multirow[t]{2}{*}{ Anthropomorphic feature ${ }^{a}$} & \multicolumn{2}{|l|}{ Women } & \multicolumn{2}{|l|}{ Men } \\
\hline & $\beta$ coefficient & $p$ value & $\beta$ coefficient & $p$ value \\
\hline Truncal fat per cent & -0.027 & $<0.0001$ & -0.033 & $<0.0001$ \\
\hline LE fat per cent & 0.035 & $<0.0001$ & 0.034 & $<0.0001$ \\
\hline
\end{tabular}

Models included anthropometric measures expressed as relative proportion of adiposity

$\beta$ coefficients refer to the estimated change in $(\mathrm{log})$ adiponectin $(\mu \mathrm{g} / \mathrm{ml})$ for each $\%$ increase in the degree of adiposity

${ }^{a}$ Model adjusted for age, ethnic background, height, total body weight, and all listed body composition variables simultaneously

LE, lower extremity

Interestingly, among this group a direct relationship between adiponectin and the degree of total body, truncal and lower extremity adiposity existed among both men and women (Table 8). Sex-specific quartile analysis demonstrated a graded increase in adiponectin levels with increasing proportion of lower extremity and truncal adiposity (Fig. 3). The gradient across quartiles was also steeper for lower extremity than truncal fat in both sexes.

\section{Discussion}

The inverse relationship between circulating adiponectin levels and composite measures of adiposity has been well described [13]. The present study extends these findings by reporting on the association of different partitions of body mass with adiponectin across sexes and ethnicities. The consistent relationships seen across groups were that adiponectin levels were higher with increasing lower extremity adiposity and decreasing truncal adiposity. In addition, total body and regional fat proportions were all positively correlated with adiponectin levels at the extremes of obesity. These findings highlight the complex interplay between different fat compartments and metabolic regulation.

Prior studies have demonstrated an association between higher degrees of lower extremity fat and glucose sensitivity. Previous data from the Dallas Heart Study showed an inverse relationship between the proportion of fat in the lower extremities and markers of the metabolic syndrome, including HOMA-insulin resistance, triacylglycerol/HDL-cholesterol ratio, C-reactive protein, and systolic blood pressure $[14,20,21]$. Similarly, improved fasting and post-load glucose tolerance were found to be associated with greater lower extremity fat mass and thigh circumference in a Dutch population [16-18]. Distinct from lower extremity adiposity, both of these cohorts as well as additional studies $[15,22]$ have shown an unfavourable association between truncal fat and most metabolic variables. A view has
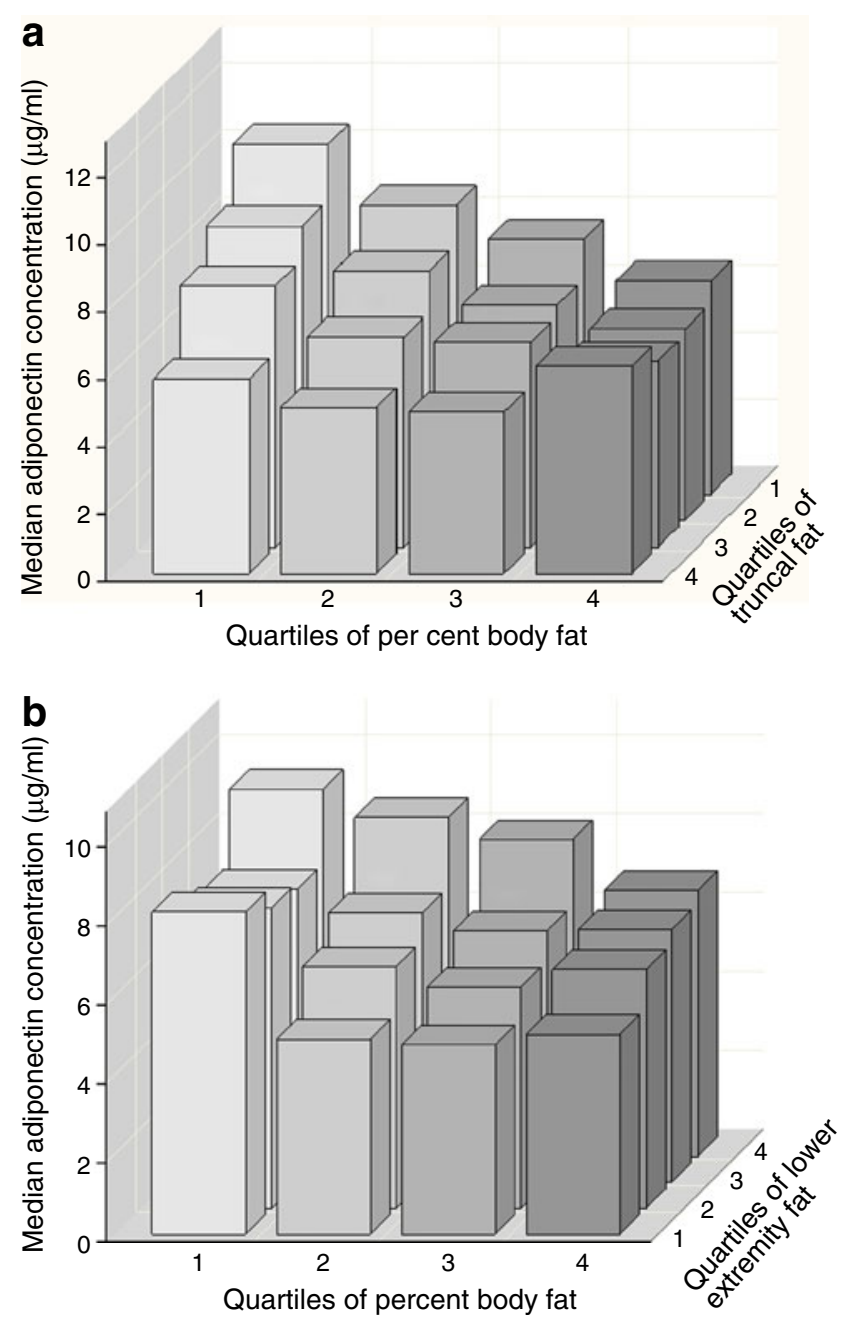

Fig. 2 Median adiponectin concentrations by sex- and ethnicitystratified quartiles of total body fat (\%) and (a) truncal or (b) lower extremity fat (\%). Increasing lower extremity adiposity is associated with higher adiponectin levels across quartiles of total body fat. The opposite finding is seen for truncal fat 

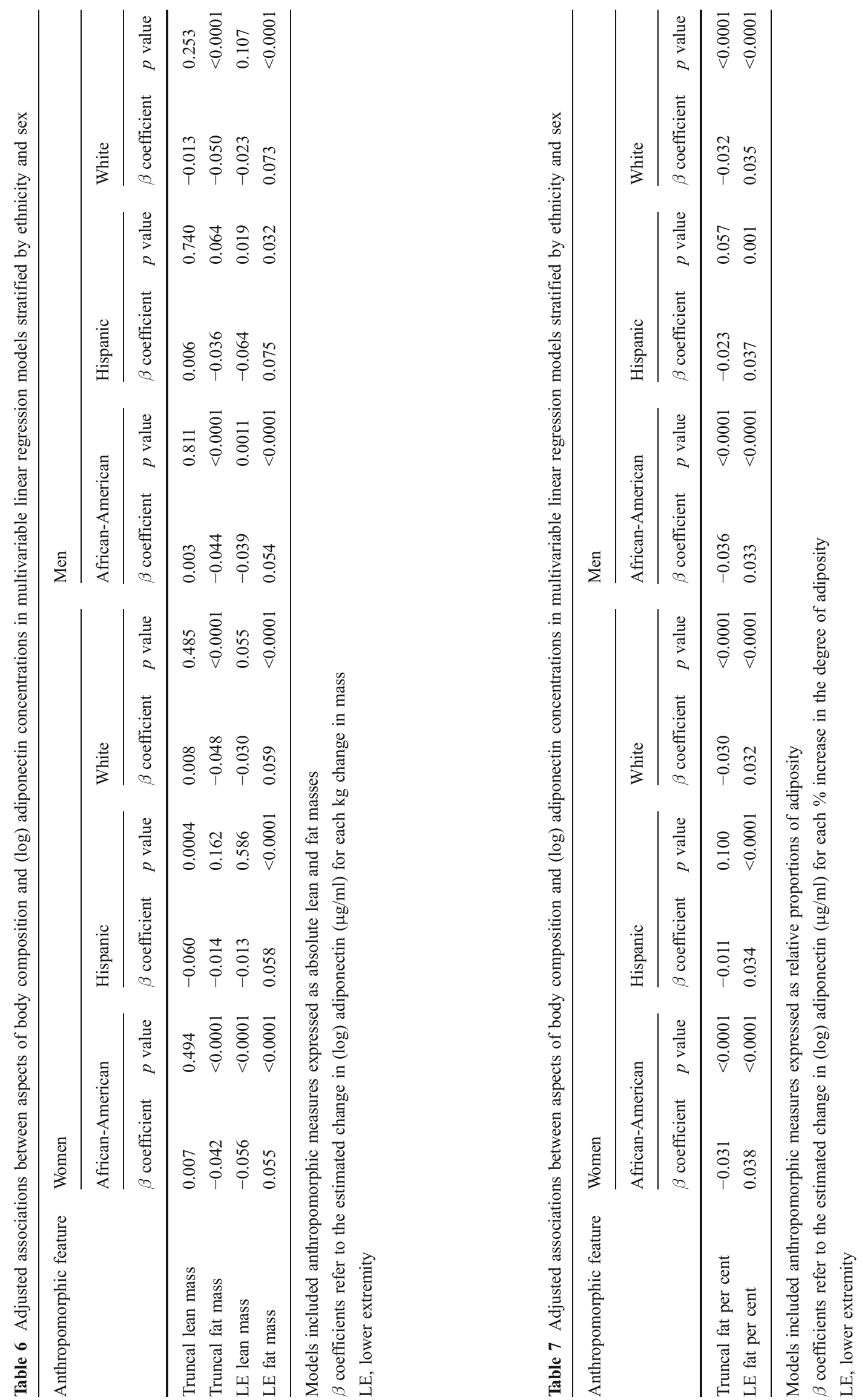
Table 8 Univariate correlations between proportion of body fat and $(\log )$ adiponectin concentrations at the upper-age- and sex-stratified tenth percentile of BMI

\begin{tabular}{|c|c|c|c|c|c|c|}
\hline \multirow[t]{2}{*}{ Anthropomorphic feature } & \multicolumn{2}{|c|}{ Both sexes $(n=280)$} & \multicolumn{2}{|c|}{ Women $(n=156)$} & \multicolumn{2}{|l|}{ Men $(n=124)$} \\
\hline & $\begin{array}{l}\text { Correlation } \\
\text { coefficient }(r)\end{array}$ & $p$ value & $\begin{array}{l}\text { Correlation } \\
\text { coefficient }(r)\end{array}$ & $p$ value & $\begin{array}{l}\text { Correlation } \\
\text { coefficient }(r)\end{array}$ & $p$ value \\
\hline Total fat per cent & 0.435 & $<0.0001$ & 0.367 & $<0.0001$ & 0.329 & 0.0002 \\
\hline Truncal fat per cent & 0.412 & $<0.0001$ & 0.278 & 0.0005 & 0.285 & 0.0014 \\
\hline LE fat per cent & 0.455 & $<0.0001$ & 0.387 & $<0.0001$ & 0.352 & $<0.0001$ \\
\hline
\end{tabular}

LE, lower extremity

emerged that lower extremity fat may be protective against risks for diabetes and metabolic syndrome. In contrast, truncal fat imparts risk for these conditions.

Earlier studies in young ( $<30$ years old), healthy men [23] and older (60-86 years old) men and women [24] had suggested a positive relationship between adiponectin and lower extremity fat while another found no association [25]. These smaller studies, however, were limited to whites with a low prevalence of overweight or obesity, a significant limitation given the racial variation in circulating adiponectin concentrations. The current analysis in a relatively large multi-ethnic population extends this association across sex, ethnicity and a wide range of body fat masses. Importantly, we found that the direct relationship between lower extremity fat and higher adiponectin levels was remarkably similar across different ethnic groups for both men and women. In distinction, an inverse relationship between truncal adiposity and adiponectin concentrations was seen among African-Americans and whites, but not Hispanics.

The differential association of various fat depots to insulin resistance is thought to relate to the pro-inflammatory [26, 27] and lipolytic characteristics [28, 29] of visceral fat relative to subcutaneous adipose tissue. Furthermore, visceral fat is an important site for IL-6 secretion that drains directly into the portal vein, thereby exerting a direct effect on the liver. Indeed, there is a significant first-pass extraction of IL- 6 of as much as $50 \%$ across the splanchnic bed [30]. Some reports demonstrate that both adiponectin mRNA levels and protein secretion are significantly lower in both cultured adipocytes [31] and tissue biopsy samples [32] from omental compared with subcutaneous (either gluteal or abdominal) sources. However, this is not necessarily a reflection of the rate of adiponectin release from the respective depots, as the release of adiponectin is primarily regulated post-translationally. Thus, circulating adiponectin levels may reflect the ability of 'healthy' adipose tissue to store fat prior to accumulation of ectopic fat deposition [33]. Our novel finding that increasing degrees of adiposity (particularly in the lower extremities) among the most obese segment of the study population was associated with higher adiponectin levels is broadly in support of this notion and consistent with the widely reported protective effects of subcutaneous depots.

To what degree adiponectin is directly playing a protective role against ectopic fat deposition, or is simply a marker of this process, is unknown in a clinical setting. However, rodent models that overproduce adiponectin strongly suggest that it is more than just a marker, but rather an adipokine that can actively improve insulin sensitivity and drive adipogenesis [3-5]. The adiponectin-
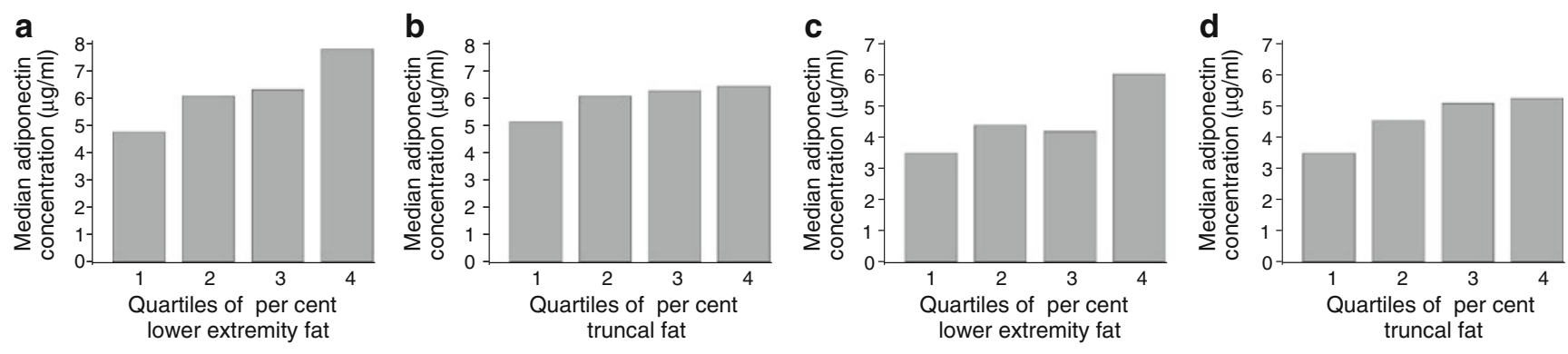

Fig. 3 Median adiponectin levels stratified by quartiles of adiposity in the lower extremities (a, c) and trunk (b, d) among (a, b) women and (c, d) men at the upper tenth percentile extreme of BMI for the study population. $p$ values refer to non-parametric ANOVA for differences

between groups: (a) $p=0.0001$; (b) $p=0.033$; (c) $p=0.002$; (d) $p<0.002$. Higher degrees of adiposity appeared to be related to greater adiponectin levels, particularly among men 
overexpressing $o b / o b$ mouse is even more obese than the $o b / o b$ mouse but, despite this finding, the adiponectinoverexpressing $o b / o b$ mouse maintains a smaller average adipocyte cross-sectional area and displays no greater visceral fat deposition than a wild-type mouse [34]. This demonstrates an improved ability to properly store fats in peripheral depots with high levels of adiponectin. Furthermore, overproduction of adiponectin appears to mimic the effects seen with chronic peroxisome proliferator-activated receptor (PPAR)- $\gamma$ agonist treatments and triggers improvements in lipid metabolism through expression of a number of genes involved with lipid metabolism and adipogenesis, including PPAR- $\gamma 2$ (also known as PPARG2) [34, 35].

The major limitation of this study is its cross-sectional nature which does not allow us to determine causality between regional fat masses and adiponectin levels. An additional limitation of this study is that levels of oligmeric forms of adiponectin were not routinely assayed in this sample cohort. Much of the biological action of adiponectin is thought to arise from the high-molecular-weight isoforms [36, 37], and total levels may only be a surrogate of this measure. However, the exact relevance of the different circulating forms for the key biological effects of adiponectin associated with its ability to lower plasma and tissue ceramide levels while increasing the levels of the ceramide degradation product sphingosine-1phosphate has not yet been examined [6].

In summary, whereas previous studies have identified the inverse relationship between circulating adiponectin levels and BMI, measures of regional body composition reveal differential and opposing associations between truncal and lower extremity fat that are very instructive. Moreover, sex and ethnic differences help to demonstrate the association of adiponectin with regional body fat. While increasing truncal fat is associated with lower adiponectin levels, lower extremity adiposity is associated with higher adiponectin levels. The relationships between adiponectin and body fat are also not constant and vary at the extremes of adiposity. These findings provide supportive evidence that regional fat depots have opposing function with respect to adipokines.

Acknowledgements We would like to thank L. Brulé in the Metabolic Core Facility for adiponectin measurements (subsidised in part by the TORS Molecular and Metabolic Mouse Phenotyping Core (5PL1DK081182; J. Horton) and by P01DK088761 (P.E. Scherer).

Contribution statement A.T.T. and P.E.S. were responsible for the conception, design, and analysis of the study and drafting of the manuscript. C.R.A. performed the statistical analyses and data interpretation. A.K., C.R.A., C.B.T., S.M.G., and G.L.V. contributed to the data analysis and interpretation, as well as manuscript revisions. All authors provided approval of the final version of the manuscript.

Duality of interest The authors declare that there is no duality of interest associated with this manuscript.

\section{References}

1. Ouchi N, Kihara S, Arita Y et al (1999) Novel modulator for endothelial adhesion molecules: adipocyte-derived plasma protein adiponectin. Circulation 100:2473-2476

2. Ouchi N, Kihara S, Arita Yet al (2000) Adiponectin, an adipocytederived plasma protein, inhibits endothelial NF- $\mathrm{KB}$ signaling through a cAMP-dependent pathway. Circulation 102:1296-1301

3. Fruebis J, Tsao TS, Javorschi S et al (2001) Proteolytic cleavage product of $30-\mathrm{kDa}$ adipocyte complement-related protein increases fatty acid oxidation in muscle and causes weight loss in mice. Proc Natl Acad Sci U S A 98:2005-2010

4. Yamauchi T, Kamon J, Waki $\mathrm{H}$ et al (2001) The fat-derived hormone adiponectin reverses insulin resistance associated with both lipoatrophy and obesity. Nat Med 7:941-946

5. Berg AH, Combs TP, Du X, Brownlee M, Scherer PE (2001) The adipocyte-secreted protein Acrp30 enhances hepatic insulin action. Nat Med 7:947-953

6. Holland WL, Miller RA, Wang ZVet al (2011) Receptor-mediated activation of ceramidase activity initiates the pleiotropic actions of adiponectin. Nat Med 17:55-63

7. Li S, Shin HJ, Ding EL, van Dam RM (2009) Adiponectin levels and risk of type 2 diabetes: a systematic review and meta-analysis. JAMA 302:179-188

8. Wolk R, Berger P, Lennon RJ, Brilakis ES, Davison DE, Somers VK (2007) Association between plasma adiponectin levels and unstable coronary syndromes. Eur Heart J 28:292-298

9. Broedl UC, Lebherz C, Lehrke M et al (2009) Low adiponectin levels are an independent predictor of mixed and non-calcified coronary atherosclerotic plaques. PLoS One 4:e4733

10. Hotta K, Funahashi T, Arita Y et al (2000) Plasma concentrations of a novel, adipose-specific protein, adiponectin, in type 2 diabetic patients. Arterioscler Thromb Vasc Biol 20:1595-1599

11. Shimada M, Kawahara H, Ozaki K et al (2007) Usefulness of a combined evaluation of the serum adiponectin level, HOMA-IR, and serum type IV collagen $7 \mathrm{~S}$ level to predict the early stage of nonalcoholic steatohepatitis. Am J Gastroenterol 102:1931-1938

12. Musso G, Gambino R, Durazzo M et al (2005) Adipokines in NASH: postprandial lipid metabolism as a link between adiponectin and liver disease. Hepatology 42:1175-1183

13. Cnop M, Havel PJ, Utzschneider KM et al (2003) Relationship of adiponectin to body fat distribution, insulin sensitivity and plasma lipoproteins: evidence for independent roles of age and sex. Diabetologia 46:459-469

14. Vega GL, Adams-Huet B, Peshock R, Willett D, Shah B, Grundy SM (2006) Influence of body fat content and distribution on variation in metabolic risk. J Clin Endocrinol Metab 91:4459-4466

15. Koster A, Stenholm S, Alley DE et al (2010) Body fat distribution and inflammation among obese older adults with and without metabolic syndrome. Obesity 18:2354-2361

16. Bos G, Snijder MB, Nijpels G et al (2005) Opposite contributions of trunk and leg fat mass with plasma lipase activities: the Hoorn study. Obes Res 13:1817-1823

17. Snijder MB, Dekker JM, Visser M et al (2004) Trunk fat and leg fat have independent and opposite associations with fasting and postload glucose levels: the Hoorn study. Diabetes Care 27:372-377

18. Snijder MB, Dekker JM, Visser M et al (2003) Larger thigh and hip circumferences are associated with better glucose tolerance: the Hoorn study. Obes Res 11:104-111

19. Victor RG, Haley RW, Willett DL et al (2004) The Dallas Heart Study: a population-based probability sample for the multidisciplinary study of ethnic differences in cardiovascular health. Am J Cardiol 93:1473-1480

20. Khera A, Vega GL, Das SR, Ayers C, McGuire DK, Grundy SM, de Lemos JA (2009) Sex differences in the relationship between 
C-reactive protein and body fat. J Clin Endocrinol Metab 94:3251-3258

21. Grundy SM, Adams-Huet B, Vega GL (2008) Variable contributions of fat content and distribution to metabolic syndrome risk factors. Metab Syndr Relat Disord 6:281-288

22. Beasley LE, Koster A, Newman AB et al (2009) Inflammation and race and gender differences in computerized tomographymeasured adipose depots. Obesity 17:1062-1069

23. Staiger H, Tschritter O, Machann J et al (2003) Relationship of serum adiponectin and leptin concentrations with body fat distribution in humans. Obes Res 11:368-372

24. Snijder MB, Flyvbjerg A, Stehouwer CD et al (2009) Relationship of adiposity with arterial stiffness as mediated by adiponectin in older men and women: the Hoorn Study. Eur J Endocrinol 160:387-395

25. Frederiksen L, Nielsen TL, Wraae K et al (2009) Subcutaneous rather than visceral adipose tissue is associated with adiponectin levels and insulin resistance in young men. J Clin Endocrinol Metab 94:4010-4015

26. Fried SK, Bunkin DA, Greenberg AS (1998) Omental and subcutaneous adipose tissues of obese subjects release interleukin-6: depot difference and regulation by glucocorticoid. J Clin Endocrinol Metab 83:847-850

27. Fain JN, Madan AK, Hiler ML, Cheema P, Bahouth SW (2004) Comparison of the release of adipokines by adipose tissue, adipose tissue matrix, and adipocytes from visceral and subcutaneous abdominal adipose tissues of obese humans. Endocrinology 145:2273-2282

28. Bolinder J, Kager L, Ostman J, Arner P (1983) Differences at the receptor and postreceptor levels between human omental and subcutaneous adipose tissue in the action of insulin on lipolysis. Diabetes 32:117-123
29. Fried SK, Russell CD, Grauso NL, Brolin RE (1993) Lipoprotein lipase regulation by insulin and glucocorticoid in subcutaneous and omental adipose tissues of obese women and men. J Clin Invest 92:2191-2198

30. Fontana L, Eagon JC, Trujillo ME, Scherer PE, Klein S (2007) Visceral fat adipokine secretion is associated with systemic inflammation in obese humans. Diabetes 56:1010-1013

31. Drolet R, Bélanger C, Fortier M et al (2009) Fat depot-specific impact of visceral obesity on adipocyte adiponectin release in women. Obesity 17:424-430

32. Fisher FM, McTernan PG, Valsamakis G et al (2002) Differences in adiponectin protein expression: effect of fat depots and type 2 diabetic status. Horm Metab Res 34:650-654

33. Hivert MF, Sun Q, Shrader P, Mantzoros CS, Meigs JB, Hu FB (2011) Higher adiponectin levels predict greater weight gain in healthy women in the Nurses' Health Study. Obesity 19:409415

34. Kim JY, van de Wall E, Laplante M et al (2007) Obesity-associated improvements in metabolic profile through expansion of adipose tissue. J Clin Invest 117:2621-2637

35. Combs TP, Pajvani UB, Berg AH et al (2004) A transgenic mouse with a deletion in the collagenous domain of adiponectin displays elevated circulating adiponectin and improved insulin sensitivity. Endocrinology 145:367-383

36. Hara K, Horikoshi M, Yamauchi T et al (2006) Measurement of the high-molecular weight form of adiponectin in plasma is useful for the prediction of insulin resistance and metabolic syndrome. Diabetes Care 29:1357-1362

37. Zhu N, Pankow JS, Ballantyne CM et al (2010) High-molecularweight adiponectin and the risk of type 2 diabetes in the ARIC Study. J Clin Endocrinol Metab 95:5097-5104 